\author{
Пиемыслав Дембовяк \\ Институт польского языка Польской АН \\ (Польша, Краков) \\ przemyslaw.debowiak@ijp-pan.krakow.pl \\ Богумил Островский \\ Институт польского языка Польской АН \\ (Польша, Краков) \\ bogumil.ostrowski@ijp-pan.krakow.pl \\ Ядвига Ванякова \\ Институт польского языка Польской АН \\ (Польша, Краков) \\ jadwiga.waniakowa@ijp-pan.krakow.pl
}

\title{
ЭТИМОЛОГИЯ В «БОЛЬШОМ СЛОВАРЕ ПОЛЬСКОГО ЯЗЫКА ПОЛЬСКОЙ АН»*
}

В задачи работы входит определение задач и способов подачи этимологических комментариев в «Большом словаре польского языка» Польской АН для всех типов слов. Дериваты объясняются путем отсылки к производящему слову, где приводится этимологическая справка в полном объеме. При объяснении родственных слов обычно дается реконструкция исходной праславянской формы, там, где возможно, объясняется развитие значения и семантическая мотивация. Для заимствований указывается не только непосредственный источник заимствования, но и приводятся возможные языки-посредники. Рассматриваются также кальки.

Ключевые слова: этимология, Большой словарь польского языка Польской $\mathrm{AH}$, заимствования, кальки.

Как следует из предисловия к словарю его редактора Петра Жмигродского ${ }^{1}$, «Большой словарь польского языка Польской Академии наук» (= Wielki słownik języka polskiego PAN, далеe - WSJP PAN) является словарем документированным,

\footnotetext{
* Работа подготовлена при финансовой поддержке программы Министерства Науки и Высшего образования «Национальная программа развития гуманитарных знаний» 2013-2018.

${ }^{1}$ CM. http://wsjp.pl/pobieranie/Zasady_opracowania WSJP.pdf c.7.
} 
т.е. таким словарем, который опирается на аутентичную материальную базу ${ }^{2}$ Базовым источником словаря является прежде всего Национальный корпус польского языка (далее - NKJP). Важным источником стал также созданный в Институте польского языка Польской АН специально для потребностей словаря вспомогательный корпус, в который вошли тексты, которых нет в NKJP. Другим источником стал польский интернет и, кроме того, собственные эксцерпции авторов статей. В ограниченной степени авторы словаря используют также другие лексикографические источники, созданные в Институте польского языка Польской АН. B WSJP PAN принимаются во внимание только те лексические единицы (слова, фразеологические единицы, пословицы и поговорки), которые засвидетельствованы в этих источниках.

WSJP PAN является словарем современного польского языка в широком смысле этого слова, так как охватывает временной период с 1945 г. Однако необходимо подчеркнуть, что с учетом специфики источников значительная часть материала приходится на последние десятилетия XX в. и начало XXI в. Кроме того, WSJP PAN является словарем дескриптивным, а не нормативным. Необходимо отметить, что авторы не исключают из описания языковые реализации, признаваемые некорректными. При этом они только ограничиваются информацией о нормативной неприемлемости отмеченных фактов на основе «Большого нормативного словаря польского языка (PWN) и стилистической характеристики субстандартных единиц.

Одновременно WSJP PAN является словарем академическим, потому что авторы стремятся использовать в наибольшей степени достижения польского языкознания XX в., особенно в области семантического, флективного, синтаксического описания лексических единиц, при том, однако, описание дается в доступной форме, так как ориентировано по возможности на очень широкий круг пользователей польского языка.

И, наконец, WSJP PAN является словарем электронным sensu stricto, а это значит, что он изначально запланирован таким, а не является перенесением в электронную форму напечатанного словаря. Благодаря этому в нем используются такие структуры словарных статей и такие формы презентации материала, которые снимают ограничения, характерные для бумажных словарей ${ }^{3}$.

В словаре будут представлены следующие виды словарных статей: отдельные самостоятельные слова (единицы односегментные = односложные), представляющие разные части речи, фразеологические единицы, наречия, имеющие высокую частотность, сокращения, аббревиатуры и отдельные собственные имена ${ }^{4}$.

Словарь можно найти в в интернете по адресу http://wsjp.pl

Как известно в задачи этимологии входит установление происхождения слова. Важно подчеркнуть, что этимологические исследования нацелены на реконструкцию самой ранней и даже первичной формы слова, его корня, а также самого

2 Первая версия принципов составления словаря, появившаяся в 2012 г., доступна по адресу http://rcin.org.pl/dibradocmetadata?from=rss\&id-53406

3 Подробнее о WSJP PAN, его истории и перспективах см. напр. Żmigrodzki 2015: 177-187.

${ }^{4}$ CM. http://wsjp.pl/pobieranie/Zasady_opracowania WSJP.pdf c. 8. 
раннего и даже первоначального значения, т. е. его этимологического значения. Затем также важна реконструкция первоначальной мотивации слова, объяснение его структуры, т.е. определение его морфологического состава. Следовательно, этимология занимается как формальной стороной словаря, так и раскрытием его семантической мотивации и семантического развития. Ни один из аспектов этой реконструкции, ни формальный, ни семантический, не может доминировать, ни один из них не может быть проигнорирован ${ }^{5}$. Здесь действует принцип, который можно назвать «законом соответствия формы и содержания», в соответствии с которым исследования развития формы должны всегда идти вместе, параллельно с изучением семантического развития ${ }^{6}$. В этимологических исследованиях используется методы сравнительно-исторической грамматики, которая основана на сопоставлении слов, исторически родственных или взаимно соответствующих друг другу, на соблюдении собственно языковых законов. О вероятности этимологии можно говорить, когда все формальные изменения, от первоначальной формы до этимологической первоосновы, поддаются объяснению на основе действия параллельных лингвистических принципов, а семантические изменения рациональны и имеют семантические параллели.

Ясно, что проблематика этимологических исследований имеет очень много аспектов, потому что форма слова не всегда может быть объяснена как унаследованная или как заимствование. Она может быть как результатом морфологических, словообразовательных процессов (как напр. польск. kawiarnia 'место, где пьют кофе'), так и семантических (расширение, сужение значения или развитие переносного значения, ср. напр. ст.-польск. biegun 'бегун, гонец’ и совр. польск. biegun в некоторых научных значениях.

Для коллектива этимологов, работающих над WSJP PAN, необычайно важен вопрос о принципах выбора заглавного слова в словаре, что определяет и просто направляет характер действий при работе с информацией о происхождении слова. B WSJP PAN графический вид словарной статьи, а также интерпретация грамматической единицы являются критериями выбора заглавного слова. В отдельных случаях описываются единицы, различающиеся орфографией (прописная / строчная буква), как напр. baran 'зверь; шкура; о человеке' - Baran 'созвездие; знак зодиака; человек-носитель этого знака'), или единицы с разной грамматической характеристикой на уровне так наз. частей речи, при этом заглавные слова, идентичные по форме, отмечены римскими цифрами, напр. piec I (глагол ), piec II (существительное); absolutnie I (наречие), absolutnie II (в роли функции); pięć I (числительное), pięć II 'оценка 5 в школе' (существительное); zielony I (прилагательное), zielony II (существительное) $)^{7}$.

${ }^{5}$ Весьма обширна литература на эту тему, ср. напр., Sławski 1958: 99-107, а из недавних работ см. [Jakubowicz 2010: 35-44].

6 Законы языкового развития, методологические приемы при реконструкции формы и значения или семантических изменений требуют особого рассмотрения, в данной работе мы не касаемся этой проблематики.

${ }^{7}$ Cp. http://wsjp.pl/pobieranie/Zasady_opracowania_WSJP.pdf, c. 8. 
Не применимо в связи с этим определение состава заглавных слов и соответствующих словарных статей по этимологическому принципу, что означало бы, как полагают авторы словаря, смешение критериев синхронного и диахронного характера. Кроме того, последовательное привлечение этимологии в соединении с учетом в словарных статьях только непосредственного источника заимствования могло бы привести к значительному увеличению числа «двойных» словарных статей (ибо для отдельных лексических значений, таких как, напр., mysz 'устройство для управления компьютером', sezon 'собрание отрезков телевизионного сериала', которые являются семантическими заимствованиями из английского языка, потребовались бы отдельные заглавные слова). Такой принцип выбора заглавного слова в WSJP PAN означает, что информация о происхождении должна быть дана отдельно для каждого значения внутри словарной статьи. Естественно, для многих заглавных слов происхождение будет общим для всех составляющих его значений ${ }^{8}$. Однако немало заглавных слов с разным происхождением составляющих его значений. Примером такой ситуации может быть многозначное ŁATA, которое в WSJP PAN имеет даже 11 значений: 1) 'кусок материала, нашиваемый на дыру в одежде, чтобы ее закрыть, или используемый для укрепления в одежде протершегося места'; 2) 'кусок материала определенного цвета, формы или с определенным рисунком на одежде, который служит ярлыком'; 3 ) ‘то, что заполняет или закрывает образовавшуюся в чем-л. дыру’; 4) ‘дополнение или актуализация более ранней версии компьютерной программы с целью устранения ошибок, добавления новых функций или увеличения эффективности его работы'; 5) 'выделяющееся на общем фоне пятно другого цвета'; 6) 'часть воловьей туши, вырезанная между окороком, передней частью задней ноги, ребрами и оковалком’; 7) ‘большая деревянная планка квадратная или прямоугольная, прибиваемая к элементам деревянной конструкции, главным образом к крыше'; 8) 'гладкая доска, служащая для выравнивания поверхности штукатурки, паркета и т. п.'; 9) 'инструмент в форме деревянной палки с делением, служащим для измерения длины и различия в высоте’; 10) техн. 'устойство в форме столба с делениями, вбитого в дно реки, для измерения уровня воды в реке'; 11) техн. 'в деревообрабатыващей промышленности тес, по размеру близкий к квадрату и толщиной от 32 мм до 10 см'. Три первые значения, а также значения пятое и шестое восходят к праслав. *lata 'лоскут, кусок; вставка, заплата (на одежде, обуви)', четвертое значение - калька англ. patch, значение седьмое и восьмое выводят из ср.-в.-нем. latte, late 'жердь, балка', а значения девятое, десятое и одиннадцатое происходят от нем. Latte 'планка, рейка' .

Принципы подачи информации о происхождении отдельных слов изменились по сравнению с тем, что было принято в начале работы над WSJP PAN и что представлено в статьях, законченных к 2012 г. (ср. выше сноску 2). Тогда было принято, что этимологическая информация будет подаваться только в словарных статьях, описывающих заимствования. С 2013 г. этимологическая информация дается

\footnotetext{
${ }^{8} \mathrm{Cp} . \mathrm{http}: / /$ wsjp.pl/pobieranie/Zasady_opracowania_WSJP.pdf, c. 9.

9 Ясно, что нем. Latte 'рейка, планка' продолжает ср.-в.-нем. latte, late 'жердь, балка'.
} 
во всех статьях с единой заглавной формой слова (за исключением собственных названий и прилагательных от этих существительных), к ним относятся следующие типы: обычные слова (существительные, прилагательные, наречия, глаголы, заимствования, числительные) и слова, наделенные определенной функцией (предлоги, частицы), а также в некоторых статьях фразеологизмы. Другими словами, объяснение приводится при каждом отдельном слове, имеющем словарную статью, а статьи, объединяющие разные слова, не содержат этимологической информации. Теперь в написанных ранее (до 2013 г.) статьях, посвященных отдельным словам, информация о происхождении слов также постепенно дополняется ${ }^{10}$.

Для родственных слов этимологическая информация обычно сводится к приведению формы, реконструированной для позднепраславянского языка, с сохранением соответствующей записи на основе данных этимологических словарей польского языка, а также обстоятельных этимологических исследований. Вот примеры:

BIAŁY $<$ праслав. *bělъ $>$

LECIEĆ < праслав. *letěti $>$

PIĘKNY < праслав. зап. *pěknъ 'пестрый, цветной, украшенный'; носовой $\varepsilon$ в piękny вторичен $>$.

В тех случаях, когда этимология слова неочевидна (напр., когда взгляды этимологов не совпадают), вслед за конкретной информацией даются отсылки к работам, которые даются в сокращенной форме. Напр., сокращение (Bor) в конце информации о происхождении слова в WSJP PAN означает, что эта информация основана на интерпретации фактов и языковых данных В. Борыся, автора «Этимологического словаря польского языка» (ESJP).

Для производных, мотивированных на синхронном уровне, указывается только производящая для них основа или словарная статья, где можно найти полную информацию о происхождении слова, напр.:

BRODATY см. broda;

CHORĄGIEWKA cM. choragiew;

SAMOTNIK cM. samotny.

В способе отсылок к другим словарным статьям для родственных слов и ранних заимствований мы следуем системе отсылок, принятой в ESJP. Следование этому принципу обеспечивает цельность и единство ссылок в зоне этимологической информации во всех словарных статьях WSJP PAN.

Для дериватов, не мотивированных на синхронном уровне, сообщается полная информация о происхождении так же, как в случае остальных родственных слов, cp.:

PRZYCHÓD - отглагольное существительное от префиксального гл. przychodzić; см. chodzić.

В определенных статьях значение праславянского этимона настолько отличается от значения (значений) польских континуантов, что возникает необходимость объяснить развитие семантики, т.е. семантический переход от праславянского

\footnotetext{
${ }^{10} \mathrm{Cp}$. http://wsjp.pl/pobieranie/Zasady_opracowania_WSJP.pdf, c. 20.
} 
значения к значению в польском языке. В таких словарных статьях мы немного останавливаемся на вопросах исторической семантики, особенно если объяснение касается неизвестных реалий славянской культуры, ср. напр.

PRZYSIĄĆ < праслав. *prisegti 'достать, дотронуться'; значение 'принести присягу, поклясться' вторично; вероятно, оно сложилось в сочетании *prisęgti zemjo 'касаться земли, брать землю', отсюда 'принести присягу, присягнуть (на земле)' в связи с торжественным ритуалом у славян принесения присяги, во время которого присягающий касался земли или землю ел, целовал либо держал в руке (Bor) ${ }^{11}$; cм. siegać.

Происхождение иностранных слов, частично или полностью заимствованных из другого языка, далее заимствований и калек определяется на основе данных словарей иностранных слов, информации из этимологических словарей, словарей национальных языков, двуязычных словарей, а также из специальных этимологических работ. Примером слова, полностью заимствованного, может служить

BULDENEŻ бот. 'декоративный куст с шарообразным соцветием, напоминающим по форме и цвету снеговые шары, встречается в парках и садах; Viburnum opulus roseum' < франц. boule de neige 'снеговой шар'.

Иноязычное слово, ставшее основой заимствования, дается в оригинальном написании (с сохранением диакритики) тогда, когда данный язык пользуется латинским алфавитом, ср. напр.:

ABAŻUR < франц. abat-jour $>$

Графическая форма чужого слова, ставшего основой заимствования, дается тогда, когда она отличается от графической формы в польском языке. В случае, если слово происходит из языка, имеющего другой алфавит, не латинский, слово, ставшее основой заимствования, приводится в транслитерации с сохранением соответствующих диакритических знаков, напр.

BORYKAĆ SIĘ < укр. borykátsja >.

Долгота (в виде черточки над буквой) обозначается исключительно в тех случаях, когда гласный долгий, ср.

LUMBAGO < лат. lumbāgō >

Значение слова в языке-источнике заимствования приводится тогда, когда отличается от значения заимствованного слова.

Ниже примеры особых ситуаций, связанных с заимствованиями:

1) данное заимствованное слово пришло из другого языка, а его написание и значение не претерпели изменения по отношению к исходному слову в языке, из которого пришло заимствование, напр.:

CICERONE < итал.>

2) данное слово заимствовано из иностранного языка, и его графическая форма изменилась по отношению к слову-источнику, которое было заимствовано, но значение слов в обоих языках тождественно, напр.:

MALTRETOWAĆ < франц. maltraiter $>$

${ }_{11}$ Как показывает сокращение (Bor), это авторское объяснение, взятое из «Этимологического словаря польского языка» В. Борыся. 
3) данное слово заимствовано из иностранного языка, его графическая форма не претерпела изменений по отношению к языку, из которого слово было заимствовано, но значение слов в языках разное, напр.:

FILIA 'отдел института, предприятия' < лат. 'дочка'>

4) данное слово заимствовано из иностранного языка, его графическая форма претерпела изменения по отношению к слову-источнику в языке, из которого слово заимствовано, при этом значения в обоих языках различаются, напр.:

ADVENT 'в католической литургии период, охватывающий четыре недели перед Рождеством' < лат. adventus 'приход'>

B WSJP PAN встречаются также заимствованные слова-цитаты. К ним применяются те же самые принципы этимологического описания, что и к другим заимствованиям, напр.:

$\mathrm{AD}$ REM < лат.>

AB OVO 'от начала' < лат. 'от яйца'>

Среди заимствований в WSJP PAN есть также интернационализмы. Если слово, будучи основой заимствования, выступает более, чем в одном языке, и нет определенности, из какого конкретного языка оно заимствовано, приводится ,internac.” или в сокращенном виде названия языков вместе с соответствующими формами слов в этих иностранных языках, напр.:

FALSYFIKATOR internac. < англ. falsificator, франц. falsificateur, нем. Falsifikator.

Достаточно часто интернационализмы состоят из морфем, истоки которых в латинском или греческом языках. Тогда этимологическое описание более длинное, оно охватывает не только формы в трех иностранных языках, но также и происхождение этой формы, а в ней греческих или латинских морфем. Выглядит это следующим образом:

LEUKOCYT биол. 'бесцветная клетка крови и лимфы, выполняющая в организме защитную функцию' internac. < англ. leucocyte, франц. leucocyte, нем. Leukozyt из н.-лат. leucocytus > < греч. leukós 'белый’ + греч. kýtos 'кувшин, сосуд; тело’>

В последнем примере видно, что если заимствованное слово состоит из заимствованных морфем, то они показаны вместе с их значениями, напр.:

MAGNETOTERAPIA мед. 'метод лечения, основанный на использовании магнитного поля' internac. < англ. magnet therapy, франц. magnétothérapie, нем. Magnettherapie > позднегреч. mágnēs, -ētos 'магнит' + греч. therapeía 'забота, почтение, лечение' >.

При заимствованиях часто имеем дело с такими ситуациями, когда в процессе заимствования какой-то язык выступает в качестве посредника. Тогда в первую очередь приводится язык, из которого слово непосредственно заимствовано в польский язык, а далее приводятся также дальние источники (если они очевидны, повсеместно известны или как-то важны), напр.:

POLITYK < нем. Politiker, из лат. polīticus >

Если какое-то слово является производным от заимствованного слова, в словаре дается отсылка к производящему слову. В указанной статье дается полная информация о происхождении слова, напр.: 
BLUESOWY < от: blues>

BEZKONFLIKTOWY < от: konflikt $>$

Объяснительная часть словаря в WSJP PAN содержит не только строго этимологическую информацию. Особое внимание к тому, что может помочь в понимании не входящего в определение значения лексической единицы. Чаще всего это касается эпонимов, крылатых слов, пословиц, фразеологизмов с компонентами, отсылающими к форме географических названий или историзмов (выражений библейских, мифологических) или терминов, состоящих из компонентов, связанных с собственными именами. В качестве примера можно привести статьи:

KURONIÓWKA простореч. 'пособие по безработице' < от имени Jacek Kuroń (1934-2004), общественный и политический деятель, министр труда и социальной политики в 1989-90 и 1992-93>.

KOŚCI ZOSTAŁY RZUCONE 'перейти Рубикон, т. е. то, что неотвратимо, обратное невозможно’ < слова, которые сказал Юлий Цезарь, переходя реку Рубикон и тем самым положив начало гражданской войне в Риме в 49 г. н.э. >.

Как сказано выше, не всегда ясно происхождение слов. Часто приходится решать, какую из этимологических версий, представленных в разных исследованиях, можно признать наиболее вероятной. Большую помощь в этом отношении оказывают этимологические словари отдельных языков, в особенности общеславянские словники, в том числе московский ЭССЯ [ЭССЯ 1-40-] или краковский “Праславянский словарь" [SP 1-8-]12. Строгое следование определенным принципам позволяет нам сделать выбор самой надежной реконструкции формы и значения, а также наиболее правдоподобной семантической мотивации ${ }^{13}$. Примером может служить слово mandarynka. Токарский [Tokarski SWO] пишет о том, что слово может происходить от mandaryn 'высокое должностное лицо, сановник и ученый в старом Китае' с учетом цвета одежды этих китайских сановников или от названия острова Mandar = Mauritius. В словаре Эльжбеты Собол [Sobol SWO] допускается только одна возможность, а именно заимствование mandarynka из франц. mandarine, котоpoе от исп. (naranja) mandarina 'апельсин с острова Мандара' (с острова Mauritius в Индийском океане) ${ }^{14}$. В этом случае единственное, что необходимо сделать, состоит в проверке происхождения слова-источника в испанском языке. Это позволяет окончательно утверждать, что франц. (orange) mandarine из исп. (naranja) mandarina, что дословно значит 'мандаринский (апельсин)', а семантической мотивацией является цвет мандарин, а не название острова Mauritius ${ }^{15}$.

12 Последующие вып. 9 и 10 в печати. В 2017 г. (под руководством М. Якубович) начата работа над 11 т. в рамках грантового проекта «Национальная программа поддержки гуманитарного знания».

${ }^{13}$ Тут не место останавливаться на принципах методологии этимологической науки, поскольку эта проблематика выходит за рамки настоящей работы.

${ }^{14}$ Такое же определение находим в словаре Баньковского (ESJPBańk). Важно отметить, что А. Баньковский был членом редколлегии Словаря иностранных слов под общей редакцией Э. Собол.

${ }^{15}$ К этому следует добавить, что остров Mauritius никогда не имел названия Mandara. Непонятно, к какому источнику восходит этимология слова в обоих словарях иностранных 
Обрабатывая информацию о происхождении слов для WSJP PAN, часто мы вынуждены вносить коррективы в ошибочные этимологии, представленные в этимологических словарях и в словарях иностранных слов. Примером может служить статья WOLONTARIUSZ < лат. voluntārius 'доброволец'>. В словаре [Sobol SWO] ошибочно сообщается о происхождении из франц. volontaire, тогда как форма слова (окончание-'usz), так и исторические свидетельства (с-u-), а также их датировка (cp. WSJP PAN s.v.) указывают на заимствование из латинского языка.

При работе над этимологией в WSJP PAN случаются ситуации, когда этимология данного слова отсутствует. Такая проблема обычно встает в словарях разговорного, старого, специального либо диалектного языка, главным образом такого, который выводится из иноязычного источника ${ }^{16}$. Происхождение многих таких слов не разработано в польском языке. Примером может служить статья PACYNKA, в которой четыре подраздела, при этом в каждом из них своя этимология. Собственно значение 'кукла на руке, приводимая в движение с помощью пальцев руки’ доставило нам много хлопот. После долгих поисков мы пришли к следующему выводу: < возможно, нем. Patsche 'рука, лапка', возможно, польск. *palcynka 'кукла, приводимая в движение пальцами руки'; этимология неясная; слово ввел Ян Штаудынгер (Jan Sztaudynger), знаток кукольного театра, который, с его слов, услышал его от дедушки > (cp. WSJP PAN s.v.) ${ }^{17}$. Довольно много таких темных слов без определенной этимологии. Перечисление их заняло бы много места. Цель этимологии - выяснить, откуда их можно вывести.

При определении происхождения слов в WSJP PAN совсем непростой является проблема калек. Правда, многие из них давно раскрыты, но в то же время для многих слов (и при том постоянно новых) допустимо предположение о том, что они воспроизводят структуру семантических элементов другого языка. Для нас проблема калек наиболее сложна, несмотря на богатую литературу на эту тему ${ }^{18}$. Если говорить в общем плане, то в современном словаре польского языка можно подозревать кальки, особенно из области экономики, политики и компьютерной техники. Определенную помощь, с большой долей осторожности, может оказать словарь А. Баньковского (ESJPBańk).

Подводя итог сказанному, следует четко отметить, что в WSJP PAN этимологическая зона сегодня не дает этимологии par excellence, сообщается только в очень кратком виде этимологическая информация, позволяющая читателю

слов , однако видно, что словари друг за другом повторяют ряд определений без глубокой проверки.

16 При этом важно отметить, что этимология занимает определенное место в старопольском словнике, представленном в Glosariusz staropolski [Decyk-Zieba I Dubisz 2008], а также в подготавливаемом этимологическом словаре польских диалектов [Waniakowa 2013: 317-325].

${ }^{17}$ В стадии подготовки статья Я. Ваняковой о происхождении слова pacynka (в разных значениях).

18 В последнее время стоит обратить внимание на полезную в этом отношении книгу Przewodnik po anglicyzmach w języku polskim. Автор еe, А. Виталиш (Alicja Witalisz), особенно много внимания уделяет английским калькам в польском языке. 
ориентироваться в происхождении слова. В связи с этим производные слова даются с отсылкой к производящим основам, и только в статьях, описывающих основные слова, можно познакомиться с более широкой информацией о происхождении слова. Несмотря на сообщение таких очень кратких сведений об этимологии, в полной мере осуществляются все принципы, методологически обязательные в исследованиях о происхождении слов. В каждом случае подробно рассматривается форма и семантика отдельных слов, при этом уделяется большое внимание вопросам хронологии, особенно важным для заимствований, поскольку много полезной информации можно извлечь из факта первой фиксации слова.

\section{Литература}

Bor. [BorSEJP]: Boryś W. Słownik etymologiczny języka polskiego. Kraków: Wydawnictwo Literackie, 2005.

Bańk. [ESJPBańk]: 1) Bańkowski A. Etymologiczny słownik języka polskiego, I-II, Wydawnictwo Naukowe PWN: Warszawa, 2000. 2) Bańkowski A. Etymologiczny słownik mowy polskiej [R], Częstochowa: Linguard, 2014.

Decyk-Zięba, Dubisz 2008: Decyk-Zięba, W., Dubisz S. (red.) Glosariusz staropolski. Dydaktyczny słownik etymologiczny. Warszawa: Wydawnictwo Uniwersytetu Warszawskiego, 2008.

Jakubowicz 2010: Jakubowicz M. Drogi słów na przestrzeni wieków. Zarys słownika motywacji semantycznych na materiale przymiotników słowiańskich odziedziczonych z prasłowiańszczyzny. Warszawa: Slawistyczny Ośrodek Wydawniczy (SOW) Instytutu Slawistyki Polskiej Akademii Nauk, 2010.

Stawski 1958: Stawski F. Uwagi o badaniach etymologicznych nad słownictwem słowiańskim. [в:] Z Polskich Studiów Slawistycznych, Językoznawstwo. Prace na IV Międzynarodowy Kongres Slawistów w Moskwie, Warszawa: Państwowe Wydawnictwo Naukowe, 1958, c. 99-107.

Sobol SWO: Słownik wyrazów obcych / pod red.: E. Sobol, wyd. I, Warszawa: Wydawnictwo Naukowe PWN, 1999.

$S P$ : Słownik prasłowiański/pod red. F. Sławskiego. T. 1-8-. Wrocław etc.: Zakład Narodowy im. Ossolińskich. Wydawnictwo Polskiej Akademii Nauk, 1974-. Следующие вып. 9 и 10 в печати.

Tokarski SWO: Słownik wyrazów obcych, red. J. Tokarski, Warszawa: Wydawnictwo Naukowe PWN, 1980.

Waniakowa 2013: Waniakowa J. Etymologiczny słownik gwar polskich — nowe zadanie w badaniach historyczno-porównawczych, Polonica, XXXIII: 317, c. 317-325.

Witalisz, A. Przewodnik po anglicyzmach w języku polskim. Biblioteczka Towarzystwa Miłośników Języka Polskiego nr 27, Kraków: Wydawnictwo JAK, 2016.

Żmigrodzki 2015: Żmigrodzki P. Wielki słownik języka polskiego PAN — historia, stan obecny i perspektywy rozwoju po 2018 roku, Biuletyn Polskiego Towarzystwa Językoznawczego, 71, 2015: 177-187. 
ESSJa: Этимологический словарь славянских языков. Праславянский лексический фонд. Под ред. О.Н. Трубачёва (Вып. 1-31), А. Ф. Журавлева (Вып. 32-39), А.Ф. Журавлева и Ж. Ж. Варбот ( 40 [*oborъkъ -*pakъla])-. Москва: Наука, 19742016-.

\author{
Przemystaw Dębowiak \\ Institute of Polish language of the Polish Academy of Sciences \\ (Krakow, Poland) \\ przemyslaw.debowiak@ijp-pan.krakow.pl \\ Bohumil Ostrowski \\ Institute of Polish language of the Polish Academy of Sciences \\ (Krakow, Poland) \\ bogumil.ostrowski@ijp-pan.krakow.pl \\ Jadwiga Waniakowa \\ Institute of Polish language of the Polish Academy of Sciences \\ (Krakow, Poland) \\ jadwiga.waniakowa@ijp-pan.krakow.pl
}

\title{
ETYMOLOGY IN THE POLISH ACADEMY OF SCIENCES GREAT DICTIONARY OF POLISH
}

The article offers an insight into etymological information provided in the Polish Academy of Sciences Great Dictionary of Polish. The dictionary and the rules of elaborating the entries are briefly presented. These rules influence the way of working on etymology in the dictionary.

The main part of the article is devoted to the presentation of the field "origin" and the etymological information which is given in one-word entries. The principles of elaborating this information in the dictionary are presented in detail and illustrated with examples. Moreover, some problems, like the issue of borrowings, calques and semantic motivation, are discussed in the paper.

Key words: etymology, Polish Academy of Sciences Great Dictionary of Polish, native words, loanwoards, calques.

\section{References}

Boryś W. Słownik etymologiczny języka polskiego [Etymological Dictionary of the Polish Language]. Kraków, Literary Publisher Publ., 2005.

Bańkowski A. 1) Etymologiczny słownik języka polskiego [Etymological Dictionary of the Polish Language]. Vol. I-II. Warszawa, Polish Scientific Publishers PWN, 2000. 2) Bańkowski A. Etymologiczny słownik mowy polskiej (R)], [Etymological Dictionary of the Polish Language (R)], Częstochowa, Linguard, 2014. 
Decyk-Zięba W., Dubisz S. (red.) Glosariusz staropolski. Dydaktyczny słownik etymologiczny. [Glossary of Old Polish: Didactic Etymological Dictionary]. Warszawa, University of Warsaw Publ., 2008.

Jakubowicz M. Drogi słów na przestrzeni wieków. Zarys słownika motywacji semantycznych na materiale przymiotników słowiańskich odziedziczonych z prasłowiańszczyzny. [Pathways of words over the centuries. Outline of the dictionary of semantic motivations based on the material of Slavic adjectives inherited from the Slavonic language]. Warszawa, Slavic Publishing Centre (SOW), The Institute of Slavic Studies, Polish Academy of Sciences (ISS PAS)], 2010.

Sławski F. Uwagi o badaniach etymologicznych nad stownictwem stowiańskim [Observation on etymological research on Slavonic vocabulary]. [In:] Z Polskich Studiów Slawistycznych, Językoznawstwo. Prace na IV Międzynarodowy Kongres Slawistów w Moskwie [From Polish Slavic Studies, Linguistics. Works for the Fourth International Slavic Congress in Moscow]. Warszawa, National Scientific Publishers PWN, 1958, p. $99-107$.

Sławski F. (Ed.). Słownik prastowiański [Proto-Slavic Dictionary]. Vol. I-VIII-. Wrocław etc., Publ. of Polish Academy of Sciences, 1974-2001-.

Sobol E. (Ed.). Stownik wyrazów obcych [Dictionary of Foreign Words]. 1. edition. Warszawa, Polish Scientific Publishers PWN, 1999.

Tokarski J. (Ed.). Stownik wyrazów obcych, [Dictionary of Foreign Words]. Warszawa, Polish Scientific Publishers PWN, 1980.

Trubachev O.N., Zhuravlev A.F. (Eds.). Etimologicheskiy slovar' slavyanskih ya$z y k o v$ [Etymological Dictionary of the Slavic Languages]. Eds. O.N. Trubachev (Iss. 1-31), A.F. Zhuravlev (Iss. 32-39), A. F. Zhuravlev, Zh. Zh. Varbot (Iss. 40). Iss. 1-40-, Moscow, Nauka Publ., 1974-2016-.

Waniakowa J. Etymologiczny stownik gwar polskich - nowe zadanie w badaniach historyczno-porównawczych [Etymological Dictionary of Polish dialects - a new task in historical-comparative research]. Polonica, XXXIII, 2013, p. 317-325.

Witalisz, A. Przewodnik po anglicyzmach w języku polskim [A guide to Anglicisms in Polish language]. Library of the Association of Polish Language Lovers No.27. Kraków, JAK Publ., 2016.

Żmigrodzki P. Wielki stownik języka polskiego PAN — historia, stan obecny i perspektywy rozwoju po 2018 roku [The Polish Academy of Sciences Great Dictionary of Polish - history, current status and perspectives of development after 2018]. Biuletyn Polskiego Towarzystwa Językoznawczego [PTJ Bulletin; PTJ = Polish Linguistic Society]. 71, Kraków, 2015, p. 177-187.

Перевела с польского языка Л. В. Куркина. 